\title{
HYDROGELS BASED ON MONOBASIC CURDLAN PHOSPHATE FOR BIOMEDICAL APPLICATIONS
}

\author{
DANA M. SUFLET, ${ }^{*}$ IRINA M. PELIN, ${ }^{*}$ VALENTINA M. DINU, \\ MIHAELA LUPU** and IRINA POPESCU* \\ *Petru Poni Institute of Macromolecular Chemistry, 41A, Grigore Ghica Voda Alley, \\ 700487, Iasi, Romania \\ *** Sanimed International IMPEX SRL, 70F, Bucharest-Magurele Rd., $5^{\text {th }}$ District, \\ 051434, Bucharest, Romania \\ 凶Corresponding author: Dana M. Suflet,dsuflet@icmpp.ro
}

Dedicated to the $70^{\text {th }}$ anniversary of the Department of Pulp and Paper, "Cristofor Simionescu" Faculty of Chemical Engineering and Environmental Protection,

"Gheorghe Asachi" Technical University of Iasi

\begin{abstract}
Novel anionic hydrogels, based on monobasic curdlan phosphate and polyvinyl alcohol, were obtained by physical cross-linking using the freeze-thaw technique. SEM and ATR-IR spectroscopy were used to analyze the morphology and the chemical structure of anionic hydrogels. The main characteristics of these new hydrogels, such as the swelling degree in pure water and phosphate buffer solution with pH 7.4 and the exchange capacity, were determined. These new hydrogels could be used as potential materials for medical applications. Therefore, the swelling behavior was studied and kinetic parameters were calculated. The Ritger-Peppas mathematical model highlighted a Fickian transport mechanism and the values obtained for the elastic modulus from mechanical tests recommend these anionic hydrogels as scaffolds for tissue engineering. The anionic hydrogels presented excellent biocompatibility.
\end{abstract}

Keywords: curdlan phosphate, anionic hydrogels, swelling behavior, mechanical test, cryogel

\section{INTRODUCTION}

Nowadays, a large interest is directed to the development of three-dimensional scaffolds for application in regenerative medicine, tissue engineering, and cell culture techniques. Cells incorporated into scaffolds can be subsequently delivered to the injured body site, where materials with controlled physical and chemical properties adapt to the biological environment and stimulate the formation of new tissue simultaneously with their own degradation. ${ }^{1-3}$ The most studied materials are hydrogels containing a natural or synthetic polymer, due to their capacity to form three-dimensional water-insoluble networks by covalent or physical cross-linking, able to retain a large amount of water or biological fluids in the case of medical applications. Natural polymers as polysaccharides have been widely used in the fields of medicine, chemicals, cosmetics, petroleum, paper and food. In the field of medicine, polysaccharides are mainly reflected in pharmaceuticals, medical biomaterials and related diseases, such as anti-cancer and hypoglycaemic products. Also, polysaccharides are frequently used to design intelligent hydrogel carriers, owing to their superior physiochemical and biological properties (e.g., biodegradability, renewability, and biocompatibility). A large number of studies regarding the use of hydrogels based on polysaccharides as drug delivery systems, scaffolds, cartilage substitute, sorbent materials have been reported in the literature, ${ }^{4-9}$ but little attention has been given to curdlan. Curdlan is a bacterial polysaccharide resulting from pure culture fermentation of Agrobacterium biobar 1, with a linear structure, composed entirely of Dglucose units linked by $\beta-(1 \rightarrow 3)$ glucosidic bonds. The current applicability of curdlan is still limited because of its insolubility in water, but this drawback can be eliminated by the introduction of ionic groups. Curdlan derivatives 
with ionic groups, such as sulfate, ${ }^{10}$ phosphate, ${ }^{11,12}$ carboxymethyl, ${ }^{13}$ and ammonium groups, ${ }^{14-16}$ have attracted a special interest due to their solubility, rheological, and biomedical properties. $^{17,18}$

However, pure curdlan produces fragile and weak hydrogels/cryogels. ${ }^{19,20}$ In this case, supporting natural and synthetic polymers, such as cellulose nanofibers ${ }^{21}$ and poly(vinyl alcohol), ${ }^{22}$ have been used as reinforcing materials.

Poly(vinyl alcohol) is a water-soluble synthetic polymer of great interest due to its many desirable characteristics: non-toxicity, noncarcinogenicity, biocompatibility, good filmforming ability and processability. Hydrogels based on poly(vinyl alcohol) are used in the biomedical area as wound dressings, ${ }^{23}$ artificial articular cartilages ${ }^{24}$ and drug delivery systems. ${ }^{25}$ Poly(vinyl alcohol) hydrogels can be prepared by chemical or physical crosslinking. Physical hydrogels (obtained by the freeze-thawing technique) have drawn greater research attention. A single or more cycles of the freeze-thawing process of a concentrated solution of poly(vinyl alcohol) leads to the formation of a network structure, without cross-linked agents. ${ }^{26}$ The hydrogels (cryogels) obtained by this method are non-toxic and their elastic properties and porosity are much better than those of poly(vinyl alcohol) hydrogels prepared by other methods.

In this paper, new anionic hydrogels based on monobasic curdlan phosphate and poly(vinyl alcohol) were obtained by physical cross-linking using the freeze-thaw technique. The morphology of the ionic hydrogels was analyzed by scanning electron microscopy and their chemical structure was confirmed by ATR-IR spectroscopy. The main characteristics of these new anionic hydrogels, such as the swelling degree in pure water and phosphate buffer solution with $\mathrm{pH} 7.4$, and the exchange capacity, were determined. These new hydrogels could be used as scaffolds for cell culture in tissue engineering. In order to verify this supposition, mechanical tests were performed and the swelling behavior of the hydrogels was studied. The Ritger-Peppas mathematical model was applied to evaluate the water transport mechanism for these new hydrogels. The hydrolytic stability in simulated biological fluid and the biocompatibility of the hydrogels were also investigated.

\section{EXPERIMENTAL}

\section{Materials}

Monobasic curdlan phosphate (PC) (with a degree of substitution up to $0.8, \mathrm{M}_{\mathrm{w}} \sim 270 \mathrm{kDa}$, determined by Gel Permeation Chromatography (GPC) measurements) was synthesized in our laboratory, using a method that was described elsewhere, ${ }^{11}$ poly(vinyl alcohol) (P) Mowiol ${ }^{\circledR} 20-98, \mathrm{M}_{\mathrm{w}}=125.000$ $\mathrm{g} / \mathrm{mol}$, degree of polymerization 2800 , degree of hydrolysis $98.0-98.8 \mathrm{~mol} \%$, was purchased from Sigma-Aldrich, GmbH, Germany. All the experiments were performed using twice-distilled water. All the solutions were prepared with distilled water.

\section{Preparation of hydrogels}

$\mathrm{PC}_{\mathrm{x}} y / \mathrm{P} z$ hydrogels were obtained by the freezingthawing $(\mathrm{F}-\mathrm{T})$ method $^{27}$ by mixing the partner solutions in different volume ratios (Table 1). The $10 \%$ $\mathrm{P}$ solution was prepared by dissolving $\mathrm{P}$ in distilled water and stirring for $2 \mathrm{~h}$ at $90{ }^{\circ} \mathrm{C}$. The PC solutions of different concentrations $(3,5,7$, and $10 \%$, w/v) were obtained by dissolving PC at room temperature under magnetic stirring. Both solutions were mixed and then were introduced into syringes with $4 \times 15 \mathrm{~mm}^{2}$ dimension. The syringes were frozen for $16 \mathrm{~h}$, at $18^{\circ} \mathrm{C}$, and then slowly thawed by keeping them for $8 \mathrm{~h}$ at room temperature (Fig. 1). The F-T process was repeated seven times. The hydrogels were washed with pure water and cut to a size of $4 \times 7 \mathrm{~mm}^{2}$. Each experiment was performed in triplicate. The overall denotation of the hydrogels is $\mathrm{PC}_{x} y / \mathrm{P} z$, wherein: $\mathrm{PC}$ stands for monobasic phosphate curdlan, $\mathrm{P}$ for poly(vinyl alcohol), $x$ is the concentration of the PC solution, $y$ shows the volume percentage of $\mathrm{PC}$ in the total polymer mixture, and $z=100-y$ shows the volume percentage of $\mathrm{P}$. For example, $\mathrm{PC}_{5} 30 / \mathrm{P} 70$ means $30 \%$ (vol) of PC solution with $5 \%(\mathrm{w} / \mathrm{v})$ concentration and $70 \%$ (vol) P.

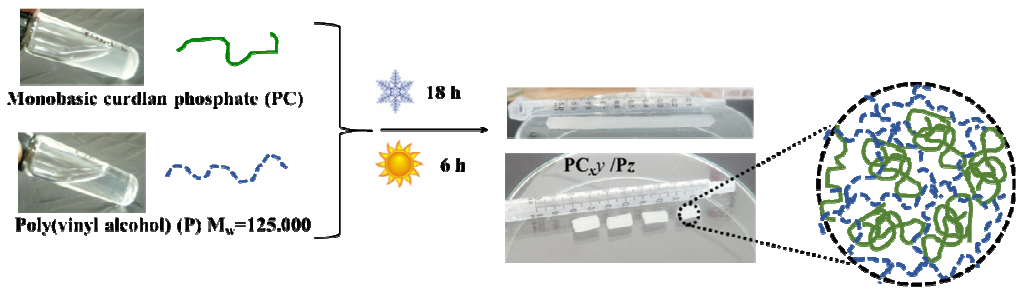

Figure 1: Preparation of $\mathrm{PC}_{\mathrm{x}} y / \mathrm{P} z$ hydrogels 
Analysis and characterization of hydrogels

Attenuated total reflection Fourier-transform infrared (ATR-FTIR) spectra were recorded on a Bruker Vertex 70 FTIR spectrometer (with coupled ATR accessory). The hydrogels morphology was evaluated by scanning electron microscopy (SEM, Quanta 200, FEI).

The exchange capacity (EC) of the hydrogels was determined by the titration method, using a 712 Metrohm conductometer with 6.0908 .110 cell for the conductometric titrations. Briefly, $100 \mathrm{mg}$ hydrogels were swollen in $20 \mathrm{~mL}$ twice-distilled water for $6 \mathrm{~h}$. After that, an excess of $0.1 \mathrm{~N} \mathrm{NaOH}$ solution $(3 \mathrm{~mL})$ was added and maintained for $2 \mathrm{~h}$ under gentle stirring, and then the solution (swollen hydrogels and the excess of $\mathrm{NaOH}$ ) were subjected to conductometric titration with a $0.1 \mathrm{~N} \mathrm{HCl}$ solution. The exchange capacity (EC) was calculated from conductometric data and expressed as meq. phosphoric groups / g dried hydrogel.

\section{Swelling behavior}

Swelling kinetics in aqueous medium was studied by the gravimetric method. Briefly, the dried hydrogel samples (weight dry, $W_{d}$ ) were immersed in phosphate buffer solution (PBS) at $\mathrm{pH} 7.4\left(\mathrm{NaH}_{2} \mathrm{PO}_{4}+\mathrm{Na}_{2} \mathrm{HPO}_{4}\right)$ or twice-distilled water at pH 5.5 (adjusted with $\mathrm{NaOH}$ or $\mathrm{HCl}$ ) at room temperature. At selected time intervals, the hydrated hydrogels were carefully taken out and weighed $\left(W_{t}\right)$ after the excess of liquid (water or PBS) was removed with a wet filter paper. This procedure was repeated until no further weight increment occurred $\left(W_{e}\right)$. The water uptake (WUT) and swelling ratio at equilibrium $\left(\mathrm{SR}_{\mathrm{eq}}\right)$ were defined as follows:

$$
\begin{aligned}
& W U T(g / g)=\frac{\left(w_{t}-w_{d}\right)}{w_{d}} \\
& S R_{g q}(g / g)=\frac{\left(w_{g}-w_{d}\right)}{w_{d}}
\end{aligned}
$$

\section{Mechanical tests}

Uniaxial compression tests on circular rods were performed using a Shimadzu mechanical test machine. The swollen samples of about $16 \mathrm{~mm}$ in diameter and $8 \mathrm{~mm}$ length were placed between two parallel plates and to ensure a complete contact between the sample and the surface of the plate. An initial compressive contact of $0.1 \mathrm{~N}$ was applied. The data were registered at a stroke of $1 \mathrm{~mm} / \mathrm{min}$. The force applied was fixed at $450 \mathrm{~N}$. The compressive stress $\left(\sigma, \mathrm{N} / \mathrm{m}^{2}\right)$ was calculated by Equation 3:

$\sigma=\frac{F}{A}$

where $F$ is the force $(\mathrm{N})$ and $A$ is the cross-sectional area of the undeformed sample $\left(\mathrm{m}^{2}\right)$.

The strain $(\varepsilon)$ was calculated with Equation 4:

$z=\frac{\Delta l}{10}$ where $\Delta l$ is the deformed length and $l_{o}$ is the initial length. The compression modulus was calculated from the slope of stress-strain curves between 0 and $10 \%$ strain.

\section{Biocompatibility assessment}

The biocompatibility of the novel composites was investigated quantitatively using MTT and LDH tests and qualitatively by Live/Dead staining, followed by subsequent observations under a confocal microscope. After 2 and 6 days of culture under standard conditions, the 3D cultures were incubated with 1 $\mathrm{mg} / \mathrm{mL}$ MTT solution (Sigma-Aldrich Co, Steinheim, Germany) in DMEM with no FBS. After $4 \mathrm{~h}$ of incubation, formazan crystals were solubilized in isopropanol, resulting in a violet solution, which was quantified spectrophotometrically at $550 \mathrm{~nm}$ using FlexStation3 (Molecular Devices, USA). The scaffold's cytotoxic effects were quantified using the Tox7 CytoToxicity Kit (Sigma-Aldrich), which is based on the measurement of lactate dehydrogenase (LDH) released from cells as a measure of cell membrane damage and cytotoxicity. The LDH release test was performed following the manufacturer's instructions and the results were represented as optical density (OD) values measured at $490 \mathrm{~nm}$. Staining of live and dead cells in the 3D cultures was investigated by using the Live/Dead kit (ThermoFisher Scientific, Foster City, CA, USA), following the manufacturer's instructions. The composites were examined by confocal microscopy (Carl Zeiss LSM 710, Jena, Germany) and images were processed with Zeiss Zen 2010 software.

\section{Biodegradability analysis}

In vitro degradation of the novel hydrogels was investigated using a protocol adapted from the literature. $^{28}$ Briefly, the hydrogels were weighed uniformly $(10 \mathrm{mg}, 1 \times 1 \mathrm{~mm})$ and subsequently immersed in lysozyme PBS solution $(10,000 \mathrm{U} / \mathrm{mL})$ and incubated at $37^{\circ} \mathrm{C}$ for 21 days. After 7,14 , and 21 days, the samples were taken out of the PBS containing lysozyme, washed with deionized water in order to remove the ions adsorbed on the surface and finally freeze-dried. The initial weight of the composites was noted as $W_{b i}$, whereas the dry weight was noted as $W_{b t}$. The percentage of degradation was calculated using the formula:

degradation $(\%)=\frac{w_{b i}-w_{b t}}{w_{b i}} \times 100$

\section{RESULTS AND DISCUSSION Preparation and characterization of hydrogels}

$\mathrm{PC}_{\mathrm{x}} y / \mathrm{P} z$ hydrogels were obtained by the $\mathrm{F}-\mathrm{T}$ method at various volume ratios between $\mathrm{P}$ and PC solutions and the influence of PC concentration was also studied. When the volume 
ratio of the $\mathrm{PC}$ solution in the hydrogel was higher than $70 \%(\mathrm{v} / \mathrm{v})$, the hydrogel did not remain in a firm form when removed from water. The mixture ratio between the polymers and the influence of the PC solution concentration in the hydrogel were studied, and the main characteristics of the hydrogels, such as the swelling ratio at equilibrium in water and PBS with $\mathrm{pH}$ 7.4, water retention, exchange capacity (EC), and elastic modulus, are presented in Table 1.

The chemical structure of the $\mathrm{PC}_{\mathrm{x}} y / \mathrm{Pz}$ hydrogel was confirmed by FTIR spectrometry. Thus, in the FTIR spectrum of the $\mathrm{PC}_{\mathrm{x}} y / \mathrm{Pz}$ hydrogel, the following characteristic bands of both partners ( $\mathrm{PC}$ and $\mathrm{P}$ ) were observed: a large band at $3292 \mathrm{~cm}^{-1}$ corresponding to the $\mathrm{OH}$ groups; a band at $2939-2908 \mathrm{~cm}^{-1}$ attributed to the $\mathrm{CH}_{2}$ and $\mathrm{CH}$ groups; the band at 1707 owing to the associated water; the band at $1649 \mathrm{~cm}^{-1}$ characteristic of $\mathrm{C}-\mathrm{OH}$ from the glucosidic units of polysaccharide chains; the bands between 1429-1237 $\mathrm{cm}^{-1}$ corresponding to $\mathrm{CH}_{2}$ bonds; the bands from $1210 \mathrm{~cm}^{-1}\left(\mathrm{P}=\mathrm{O}\right.$ bond) and $845 \mathrm{~cm}^{-1}$ (P-O-C bond) could not be identified because they overlap the characteristic polyvinyl alcohol bands.

The microstructure of hydrogels can directly influence their applications by the size of their pores or their density. Therefore, the morphology of the $\mathrm{PC}_{\mathrm{x}} y / \mathrm{P} z$ hydrogels was investigated by scanning electron microscopy. The SEM images showed a porous structure of the $\mathrm{PC}_{\mathrm{x}} y / \mathrm{P} z$ samples with pore sizes from 8 to $20 \mu \mathrm{m}$ (Fig. 2). The thickness of pore walls increased with the increase of the concentration of the PC solution and the pore size decreased with the increase in the quantity of PC in the hydrogel, as observed by SEM analyses (Fig. 3).

Table 1

Main characteristics of $\mathrm{PC}_{\mathrm{x}} y / \mathrm{Pz}$ hydrogels

\begin{tabular}{lcccccc}
\hline \multirow{2}{*}{ Sample } & \multicolumn{2}{c}{$\mathrm{SR}_{\mathrm{eq}}(\mathrm{g} / \mathrm{g})$} & & $\mathrm{EC}$ & & \multicolumn{2}{c}{ Elastic modulus } \\
\cline { 2 - 3 } & water & $\mathrm{pH} \mathrm{7.4}$ & & (meqiv./g) & $(\mathrm{Pa})$ & $\mathrm{R}^{2}$ \\
\hline $\mathrm{PC} 0 / \mathrm{P} 100$ & 4.17 & 3.22 & & - & 236.74 & 0.999 \\
$\mathrm{PC}_{5} 30 / \mathrm{P} 70$ & 8.78 & 7.90 & & 1.428 & 78.00 & 0.991 \\
$\mathrm{PC}_{5} 50 / \mathrm{P} 50$ & 11.87 & 9.18 & & 1.533 & 126.00 & 0.997 \\
$\mathrm{PC}_{5}$ 70/P30 & 13.83 & 10.2 & 1.550 & 408.00 & 0.995 \\
\hline $\mathrm{PC}_{3} 50 / \mathrm{P} 50$ & 10.81 & 11.09 & 1.513 & 78.60 & 0.996 \\
$\mathrm{PC}_{5} 50 / \mathrm{P} 50$ & 11.87 & 9.18 & & 1.553 & 126.00 & 0.997 \\
$\mathrm{PC}_{7} 50 / \mathrm{P} 50$ & 12.47 & 8.15 & & 1.641 & 148.50 & 0.996 \\
$\mathrm{PC}_{10} 50 / \mathrm{P} 50$ & 14.56 & 6.90 & 1.860 & 350.01 & 0.996 \\
\hline
\end{tabular}
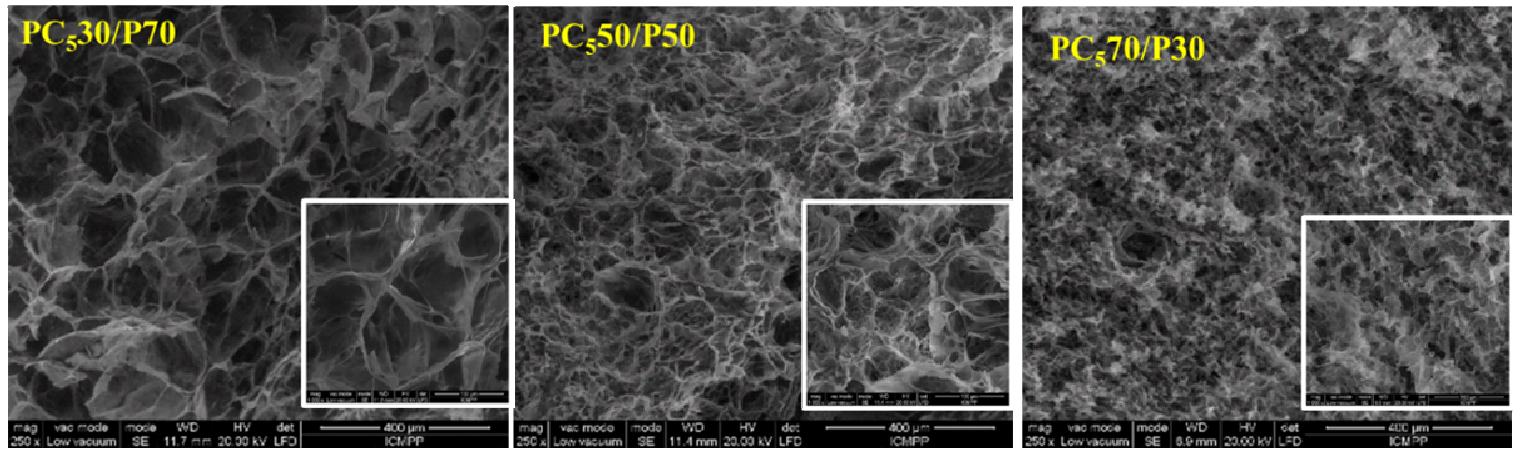

Figure 2: SEM images of hydrogels with different mixing ratios

These results indicated that the mixing ratio and PC concentration played a significant role in regulating the size and shape of the pores during the process of obtaining the hydrogels. It has also been observed that the ionic polysaccharide participates both in the structure of the hydrogel through hydrogen bonds and as a porogen.

As expected, EC values, listed in Table 1, increased both with increasing PC solution concentration and with increasing $\mathrm{PC}$ content in 
the hydrogel. In the first case, the increase was higher due to the introduction of a higher number of phosphate groups than in the second case, when the concentration remained constant.
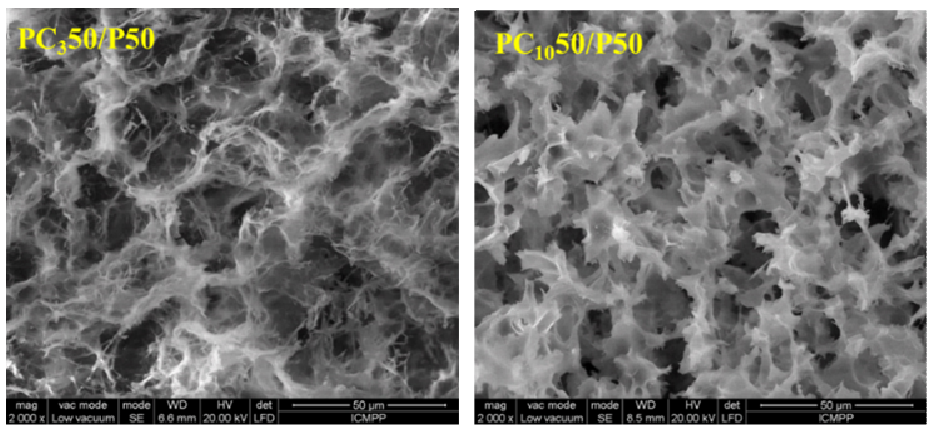

Figure 3: SEM images of hydrogels - influence of PC solution concentration

\section{Swelling kinetics of hydrogels}

Dynamic swelling studies of the anionic hydrogels were performed in order to understand both the effect of the mixing ratio between the partners ( $\mathrm{PC}$ and $\mathrm{P}$ ), and the influence of the concentration of PC solution used in the preparation of the hydrogels.

Figure 4 presents the swelling kinetics in pure water and PBS pH 7.4 for hydrogels with different mixing ratios and at different concentrations of the PC solution. All the
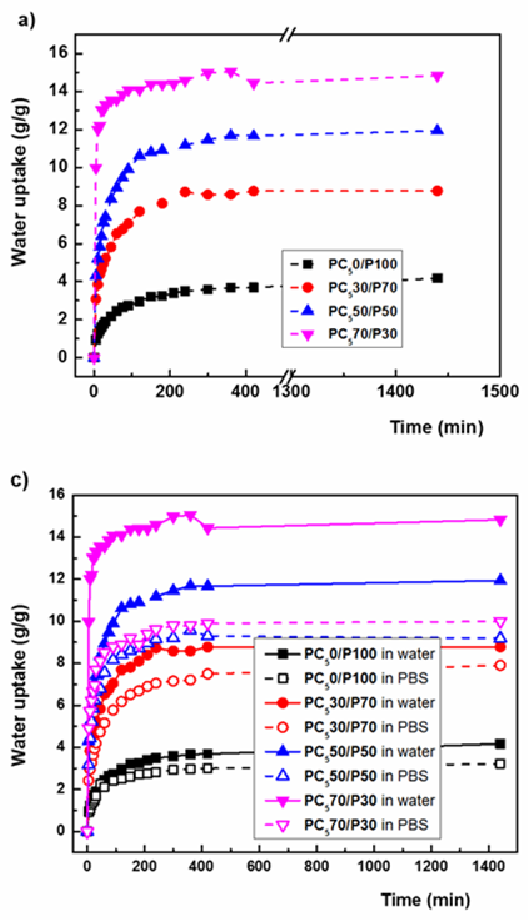

hydrogel samples rapidly hydrated in the first three hours and approached the equilibrium after six hours.

As can be seen, the swelling ability of the $\mathrm{PC}_{\mathrm{x}} y / \mathrm{Pz}$ hydrogels increased with raising the $\mathrm{PC}$ content. The $\mathrm{PC}_{5} 70 / \mathrm{P} 30$ sample showed a maximum swelling ratio in water of 14.83 , compared to 4.17 in the case of the pure polyvinyl alcohol hydrogel $\left(\mathrm{PC}_{5} 0 / \mathrm{P} 100\right)$ (Table 1$) .{ }^{22}$
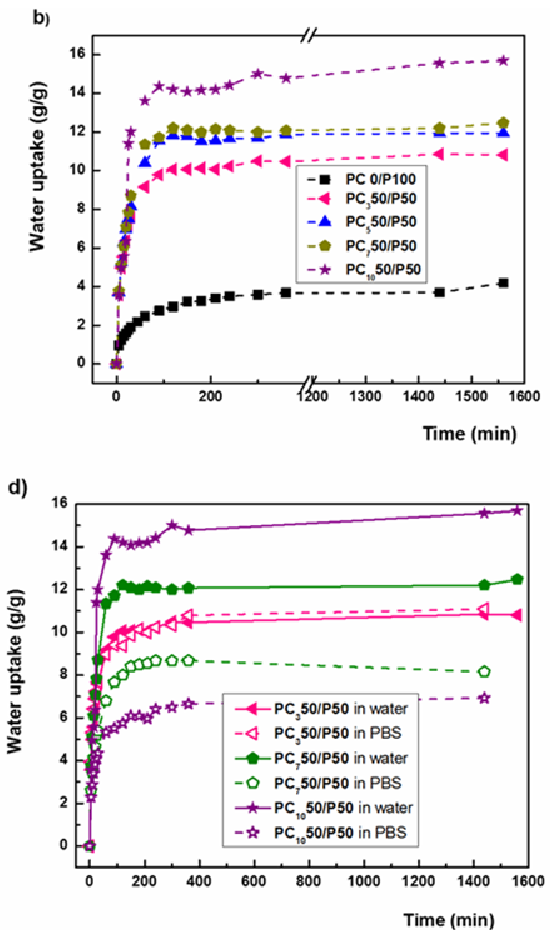

Figure 4: Swelling behavior of $\mathrm{PC}_{x} y / \mathrm{P} z$ hydrogels in water (a and $\mathrm{b}$ ); water uptake in pure water vs. phosphate buffer solution with $\mathrm{pH} 7.4$ (c and d) 
For the $\mathrm{PC}_{\mathrm{x}} y / \mathrm{P} z$ hydrogels, when the content of poly(vinyl alcohol) decreased, the swelling ratio increased because the physical cross-linked density of the hydrogel network decreased and the molecular entanglement between PC and P was weakened, which led to an improvement of the hydrogel's swelling ability. At the same time, the swelling capacity was strongly influenced by the ionic charge and the hydrophilicity of the polysaccharide, so that the swelling capacity increased with the increase of the ionic charge due to the increase of the number and force of electrostatic repulsions from phosphate groups. Also, these results can be explained by the fact that the presence of a larger amount of poly(vinyl alcohol) in the hydrogel enhanced the physical cross-linking density of the network, which in turn restricted the mobility and relaxation of the polymeric chains.

In Figures $4 \mathrm{c}$ and $4 \mathrm{~d}$, the influence of the medium $\mathrm{pH}$ on the swelling ratio of the anionic

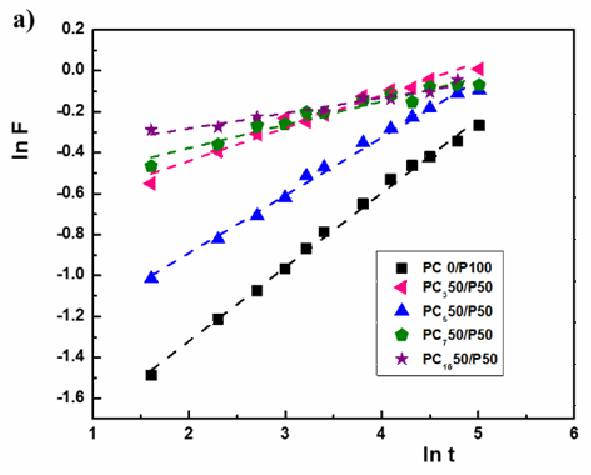

hydrogels is presented. Obviously, the non-ionic hydrogels (PC0/P100) are not sensitive to the ionic strength of the medium, the degree of swelling being approximately the same in different media. When ionic groups are present in the hydrogels, the swelling degree is influenced by the $\mathrm{pH}$ of the medium and by the ionic strength. In all the cases, it can be observed that the swelling degree is higher in water, compared with that in buffer solution. In water (without ionic strength), the chains of phosphorylated curdlan are extended due to the electrostatic repulsion between the phosphate groups, leading to the swelling of the hydrogels, while at high ionic strength (in PBS), the electrostatic repulsions are shielded. ${ }^{7,29}$ Also, with the increase of the PC content, the hydrophilic nature of the hydrogel increases, which allows enhanced swelling.

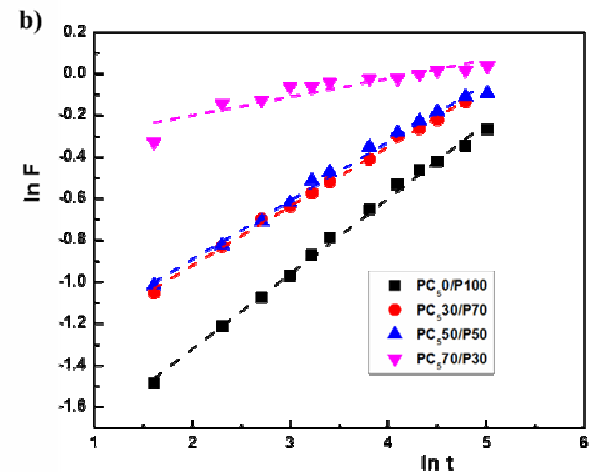

Figure 5: Plot of Ritger-Peppas model of $\mathrm{PC}_{\mathrm{x}} \mathrm{y} / \mathrm{P} z$ hydrogels

The Ritger-Peppas diffusion model, described by Equation 6, was considered to fit the experimental data. This model was originally developed to study the diffusion of small molecules, such as drugs and water, through hydrogel materials with different shapes (slabs, spheres, cylinders or discs), which do not swell more than $25 \%$ of their original volume. ${ }^{30}$

$F=\frac{M_{t}}{M_{s e}}=\frac{W V T}{5 R_{q Q}}=k \cdot t^{n}$

where $F$ is the water fraction at time $t, M_{t}$ and $M_{\infty}$ are the swelling weight of the hydrogel at $t$ and infinite time, $k$ is the kinetic constant of water diffusion into the network, and $n$ is the swelling exponent characteristic of the sample geometry and the physical mechanism of water uptake.
According to the criteria for swelling kinetics of cylinder systems, the diffusion exponent values indicate: i) $\mathrm{n} \leq 0.45$, a Fickian diffusion mechanism, when the molecular relaxation of the polymer structure is faster than the diffusion process; ii) $0.45<\mathrm{n}<0.89$, an anomalous (nonFickian) diffusion mechanism, when the diffusion and relaxation rates are comparable; iii) a Case-II transport leading to zero-order diffusion, when $n$ $=0.89$, when the diffusion is faster than the relaxation rate; iv) a super-Case-II transport of the drug, when $n>0.89$.

As regards the water uptake of the PC/P hydrogels, the values of diffusion constant $k$ and diffusional exponent $n$, as well as the corresponding linear regression correlation coefficient $\mathrm{R}^{2}$, are presented in Table 2 . The $n$ 
values for all the hydrogels were found to be between 0.075-0.362. These values show a Fickian diffusion mechanism of water into the hydrogel structure. This means that the molecular relaxation of the polymer network is faster than the diffusion process.

The value of $k$ constant also depends on the water uptake mechanism. In the case of the hydrogels with high content of ionic polysaccharide (PC), a high value of $k$ constant was obtained, which involved a low value of the $n$ coefficient. This situation suggests a low density of the crystallites of poly(vinyl alcohol) in the $\mathrm{PC}_{\mathrm{x}} y / \mathrm{Pz}$ hydrogel structure, ${ }^{8}$ which may be associated with soft hydrogels. The decrease of the $k$ value and, implicitly, the increase in the value of $n$ suggest a higher density of the crystallites in the network structure, which promotes stronger hydrogels. ${ }^{25}$

\section{Mechanical test}

The influence of the initial concentration of PC and the mixing ratio between the partners in the new hydrogels was also studied from the point of view of the mechanical properties. The elastic modulus of all the $\mathrm{PC}_{x} y / \mathrm{Pz}$ hydrogels was determined from the slope of the linear dependence of the stress-strain curves (insets of Fig. 6) and the data obtained were listed in Table 1. As can be observed from Figure 6 and Table 1, the elastic properties of the equilibrium swollen $\mathrm{PC}_{x} y / \mathrm{P} z$ hydrogels depend on the initial polysaccharide concentration and on the ratio between the components. The values of the elastic modulus increased with the increase of both the initial polysaccharide concentration and the poly(vinyl alcohol) content. The hydrogel without polysaccharide ( $\mathrm{PC} 0 / \mathrm{P} 100)$ was very weak in comparison with the anionic hydrogels, its fracture was observed at $65 \%$ of strain. The stress at fracture for the $\mathrm{PC} / \mathrm{P}$ hydrogels increased gradually as the concentration of polysaccharide increased from $3 \%$ to $10 \mathrm{wt} \%$ with a fracture strain of $78 \%$ and $85 \%$ registered only for the samples containing $3 \%$ or 5 wt $\%$ of polysaccharides (Fig. 6A). The $\mathrm{PC}_{7} 50 / \mathrm{P} 50$ and $\mathrm{PC}_{10} 50 / \mathrm{P} 50$ hydrogels were very elastic without any crack development during the compression tests. A significant rise of the stress at fracture was also observed with the increase of the poly(vinyl alcohol) content (Fig. 6B). The sample $\mathrm{PC}_{5} 30 / \mathrm{P} 70$ was highly stable against the compressive stress applied (Fig. 6C). It should be pointed out that, after the release of the load, the $\mathrm{PC}_{5} 30 / \mathrm{P} 70$ sample immediately recovers its original shape. The values obtained for the elastic modulus (126-350 Pa) recommend these new anionic hydrogels to be used as scaffolds for cell culture in tissue engineering. ${ }^{1-3}$

Table 2

Kinetic exponent $n$ and characteristic constant $k$ of water penetrating through hydrogels (data obtained from fitting experimental data)

\begin{tabular}{lccc}
\hline Sample & $\mathrm{n}$ & $\mathrm{k}$ & $\begin{array}{c}\text { Correlation } \\
\text { factor }\left(\mathrm{R}^{2}\right)\end{array}$ \\
\hline $\mathrm{PC} 0 / \mathrm{P} 100$ & 0.362 & 0.129 & 0.9964 \\
$\mathrm{PC}_{5} 30 / \mathrm{P} 70$ & 0.285 & 0.225 & 0.9974 \\
$\mathrm{PC}_{5} 50 / \mathrm{P} 50$ & 0.282 & 0.234 & 0.9922 \\
$\mathrm{PC}_{5} 70 / \mathrm{P} 30$ & 0.089 & 0.687 & 0.8349 \\
\hline $\mathrm{PC}_{3} 50 / \mathrm{P} 50$ & 0.161 & 0.467 & 0.9709 \\
$\mathrm{PC}_{5} 50 / \mathrm{P} 50$ & 0.282 & 0.234 & 0.9922 \\
$\mathrm{PC}_{7} 50 / \mathrm{P} 50$ & 0.114 & 0.545 & 0.9417 \\
$\mathrm{PC}_{10} 50 / \mathrm{P} 50$ & 0.075 & 0.649 & 0.9393 \\
\hline
\end{tabular}

\section{Biodegradability assessment}

No statistically significant differences were obtained in terms of biodegradability between the various tested hydrogels. After one week of lysozyme incubation, all the hydrogels exhibited around $10 \%$ degradation. After 14 days, all the tested hydrogels showed a degradation percentage of around $22 \%$, whereas after 21 days, the degradation reached 24-25\% (Fig. 7).

\section{In vitro biocompatibility}

After 2 days of culture under standard conditions, MTT assay results revealed a good cytocompatibility on all the tested materials, with a slightly increased viability for the $\mathrm{PC}_{7} 70 / \mathrm{P} 30$ composite.

After being cultured for 6 days, the tested composites harbored different levels of 
proliferation. The control system showed a statistically higher proliferation rate $(\mathrm{p}<0.01)$ after 6 days in comparison to the level obtained after 2 days. Similar results were obtained for L929 cells cultured on $\mathrm{PC}_{5} 70 / \mathrm{P} 30, \quad \mathrm{PC}_{5} \quad 50 / \mathrm{P} 50$ and $\mathrm{PC}_{7} 50 / \mathrm{P} 50$, which showed increased viability after 6 days of culture. When comparing the proliferation after 6 days on all the tested composites, the $\mathrm{PC}_{5} 70 / \mathrm{P} 30$ hydrogels harbored the highest statistically significant increase $(\mathrm{p}<$ $0.001)$.
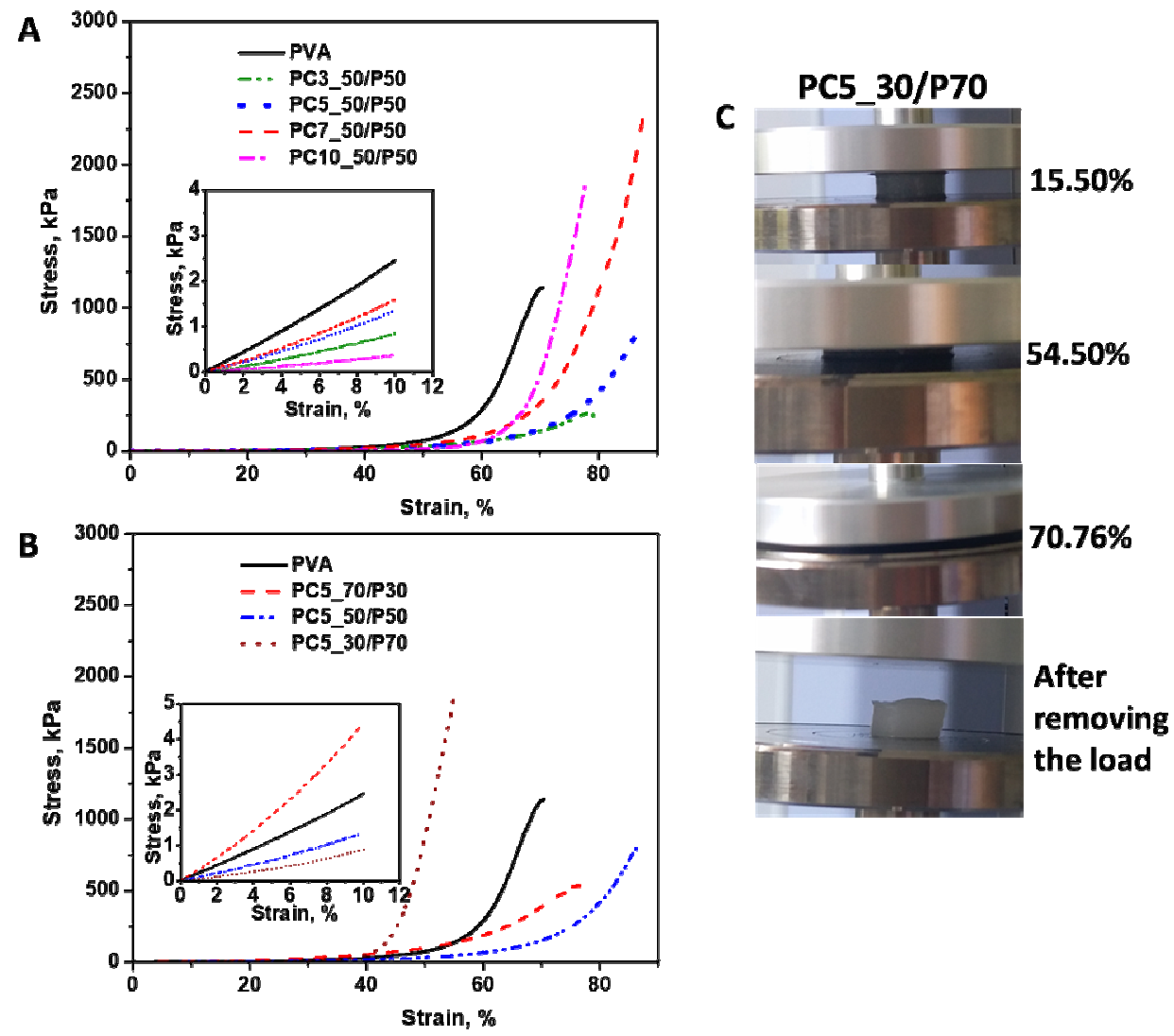

Figure 6: Typical stress-strain curves for hydrogels prepared with various initial polysaccharide concentrations (A) and different ratios between $\mathrm{PC}$ and $\mathrm{P}(\mathrm{B})$; the insets present the linear dependence of stress-strain curves between 0 and $10 \%$ compressions, which was used to calculate the elastic modulus of all hydrogels; (C) Optical pictures of swollen $\mathrm{PC}_{5} 30 / \mathrm{P} 70$ hydrogel during the uniaxial compression test

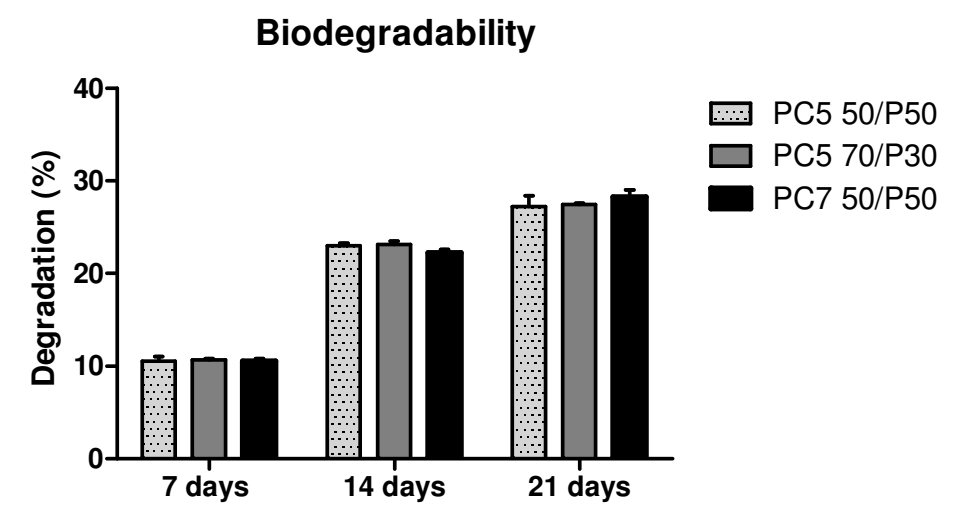

Figure 7: Biodegradation of composites after 7, 14, and 21 days of lysozyme incubation 
The composites' cytotoxicity was investigated by the LDH assay in order to quantitate the level of LDH enzyme released in the cell culture media. Our results indicate that after 2 days of culture, the tissue scaffolds harbored similar cytotoxicity compared to the control (Fig. 8A). After 6 days, the cytotoxicity of the materials increased slightly, but remained at approximately the same level as the control. No statistically significant

A)
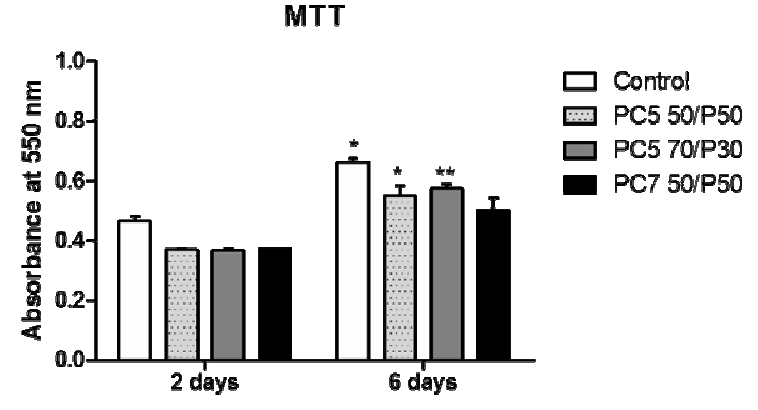
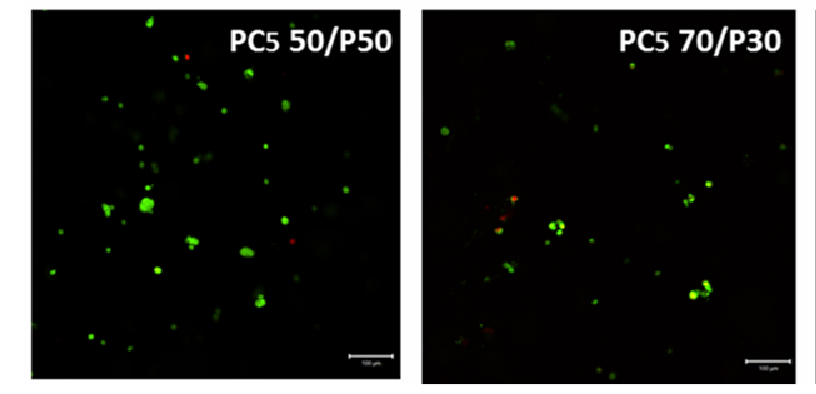

difference was found between the LDH levels released by the tested composites (Fig. 8B).

Live/Dead staining was performed in order to reveal cell dispersion inside the materials and the proportion of live (green) and dead (red) cells. The confocal microscopy analysis showed consistency with the MTT and LDH assays. Thus, the overall number of viable cells was much higher than the number of dead cells for all the tested composites (Fig. 8C).

B)

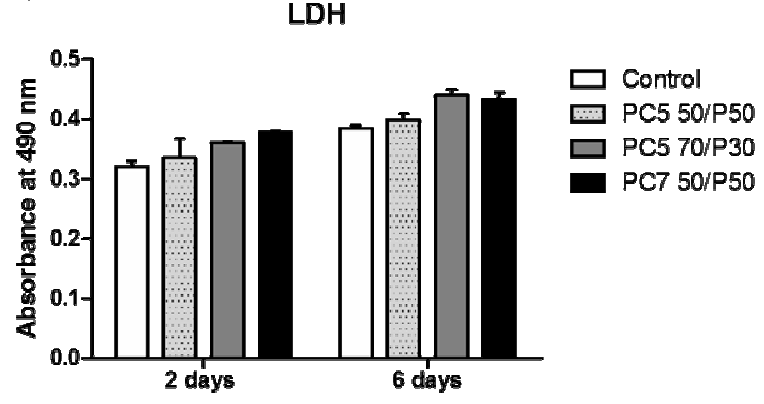

Figure 8: A) Quantitative evaluation of cell viability and proliferation on day 2 and 6 of culture, using the MTT assay; B) Quantitative evaluation of material's cytotoxicity after 2 and 6 days of culture, using the LDH assay; C) Confocal microscopy of live (green) and dead (red) cells after 2 and 6 days of culture

\section{CONCLUSION}

New anionic hydrogels based on monobasic curdlan phosphate and polyvinyl alcohol were obtained by physical cross-linking using the freeze-thaw technique. The morphology of the anionic hydrogels was analyzed by scanning electron microscopy and the chemical structure was confirmed by ATR-IR spectroscopy. The main characteristics of these new hydrogels, such as the swelling degree in pure water and phosphate buffer solution with $\mathrm{pH} 7.4$, and the exchange capacity, were determined.

The swelling behavior and kinetic parameters determined by Ritger-Peppas mathematical model highlighted a Fickian transport mechanism.
The mechanical tests have shown very elastic hydrogels, without cracking during compression tests. Furthermore, the $\mathrm{PC}_{5} 30 / \mathrm{P} 70$ hydrogels were highly stable against the compressive stress applied and quickly recovered their original shape. The values obtained for the elastic modulus (126-350 Pa) propose these new hydrogels to be used as scaffolds for cell culture in tissue engineering.

The biological tests confirmed the biocompatibility of PC/P hydrogels and a good stability in biological fluids.

ACKNOWLEDGEMENTS: The authors acknowledge the financial support of this research through the Project "Partnerships for knowledge 
transfer in the field of polymer materials used in biomedical engineering" ID_40_443, Contract no. 86/8.09.2016, MY SMIS 105689, co-financed by the European Regional Development Fund by the Competitiveness Operational Programme 20142020, Axis 1 Research, Technological Development and Innovation in support of economic competitiveness and business development, Action 1.2.3 Knowledge Transfer Partnerships.

\section{REFERENCES}

1 G. D. Nicodemus and S. J. Bryant, Tissue Eng.: Part B, 14, $149 \quad$ (2008), http://doi:10.1089/ten.teb.2007.0332

2 D. Diekjürgen and D. W. Grainger, Biomaterials, 141 , 96

(2017), http://doi:10.1016/j.biomaterials.2017.06.020

3 S. Tiwari, R. Patil and P. Bahadur, Polymers, 11, 1 (2019), http://doi:10.3390/polym11010001

4 H. Zhang, F. Zhang and J. Wu, React. Funct. Polym., 73, 923 (2013), http://dx.doi.org/10.1016/j.reactfunctpolym.2012.12.01 4

5 H. Hosseinzadeh, Cellulose Chem. Technol., 51, 529 (2017),

http://www.cellulosechemtechnol.ro/pdf/CCT56(2017)/p.529-537.pdf

6 M. Popa, B. C. Ciobanu, L. Ochiuz, J. Desbrieres, C. S. Stan et al., Cellulose Chem. Technol., 52, 353 (2018),

http://www.cellulosechemtechnol.ro/pdf/CCT56(2018)/p.\%20353-370.pdf

7 D. M. Suflet, I. Popescu and I. M. Pelin, Cellulose Chem. Technol., 51, 23 (2017), http://www.cellulosechemtechnol.ro/pdf/CCT12(2017)/p.23-34.pdf

8 F. Ullah, M. B. H. Othman, F. Javed, Z. Ahmad and H. Md. Akil, Mat. Sci. Eng. C, 57, 414 (2015), http://dx.doi.org/10.1016/j.msec.2015.07.053

9 Q. Chen, X. Shao, P. Ling, F. Liu, G. Han et al., Eur. J. Med. Chem., 139, 926 (2017), http://dx.doi.org/10.1016/j.ejmech.2017.08.048

10 P. Li, X. Zhang, Y. Cheng, J. Li, Y. Xiao et al., Carbohyd. Polym., 102, $852 \quad$ (2014), http://dx.doi.org/10.1016/j.carbpol.2013.10.078

11 D. M. Suflet, A. Nicolescu, I. Popescu and G. C. Chitanu, Carbohyd. Polym., 84, 1176 (2011), http://doi:10.1016/j.carbpol.2011.01.010

12 X. Chen, X. Xu, L. Zhang and F. Zeng, Carbohyd. Polym., 78, $581 \quad$ (2009), http://doi:10.1016/j.carbpol.2009.05.019
13 Y. Jin, H. Zhang, Y. Yin and K. Nishinari, Carbohyd. Res., 341, 90 (2006), https://doi.org/10.1016/j.carres.2005.11.003

14 D. M. Suflet, I. Popescu, I. M. Pelin, A. Nicolescu and G. Hitruc, Carbohyd. Polym., 123, 396 (2015), http://dx.doi.org/10.1016/j.carbpol.2015.01.050

15 I. Popescu, I. M. Pelin, G. L. Ailiesei, D. L. Ichim and D. M. Suflet, Carbohyd. Polym., 224, 115157 (2019), https://doi.org/10.1016/j.carbpol.2019.115157

16 Y. Tong, T. Ganbold and H. Baigude, Carbohyd. Polym., $\quad$ 175, 739 (2017), http://dx.doi.org/10.1016/j.carbpol.2017.08.037

17 R. Zhang and K. J. Edgar, Biomacromolecules, 15, 1079 (2014), https://doi.org/10.1021/bm500038g

18 F. Y. Kagimura, M. A. A. da Cunha, A. M. Barbosa, R. F. H. Dekker and C. R. M. Malfatti, Int. J. Biol. Macromol., 72, $588 \quad$ (2015), http://dx.doi.org/10.1016/j.ijbiomac.2014.09.008

19 J. Nie, B. Pei, Z. Wang and Q. Hu, Carbohyd. Polym., 205, $225 \quad$ (2019), https://doi.org/10.1016/j.carbpol.2018.10.033

20 I. Popescu, I. M. Pelin and D. M. Suflet, Int. J. Polym. Mater., 67, $1069 \quad$ (2018), https://doi.org/10.1080/00914037.2017.1417289

${ }^{21}$ M. E. El-Naggara, A. M. Abdelgawad, A. Tripathi and O. J. Rojas, J. Environ. Chem. Eng., 5, 5754 (2017), http://dx.doi.org/10.1016/j.jece.2017.10.056

22 X. Qi, X. Hu, W. Wei, H. Yu, J. Li et al., Carbohyd. Polym., 118, 60 (2015), http://dx.doi.org/10.1016/j.carbpol.2014.11.021

23 J. O. Kim, J. K. Park, J. H. Kim, S. G. Jin, C. S. Yong et al., Int. J. Pharm. 359, 79 (2008), https://doi.org/10.1016/j.ijpharm.2008.03.021

24 M. Kobayashi and M. Okaj, Biomater. Sci. Polym. Ed., $\quad$ 5, $741 \quad$ (2004), https://doi.org/10.1163/156856204774196135

25 B. E. Jensen, I. Davila and A. N. Zelikin, J. Phys. Chem. B., 120, $5916 \quad$ (2016), https://doi.10.1021/acs.jpcb.6b01381

26 J. I. D. Agudelo, J. M. Badano and I. Rintoul, Mater. Chem. Phys., 216, 14 (2018), https://doi.org/10.1016/j.matchemphys.2018.05.038

27 N. A. Peppas and S. R. Stauffef, J. Control. Release, 16, 305 (1991), https://doi.org/10.1016/01683659(92)90178-T

28 A. Mohandas, S. Kumar, B. Raja, V.-K. Lakshmanan and R. Jayakumar, Int. J. Nanomed., 10, 53 (2015), https://doi.org/10.2147/IJN.S79981

29 I. Popescu, I. M. Pelin, M. Butnaru, G. Fundueanu and D. M. Suflet, Carbohyd. Polym., 94, 889 (2013), https://doi.org/10.1016/j.carbpol.2013.02.014

30 P. L. Ritger and N. A. Peppas, J. Control. Release, 5, 37 (1987), https://doi.org/10.1016/01683659(87)90034-4 